\title{
Intravenous indomethacin for patent ductus arteriosus
}

\author{
I J SMITH, I GOSS, AND P J CONGDON
}

Regional Neonatal Intensive Care Unit, General Infirmary at Leeds, and Department of Paediatrics and Child Health, University of Leeds

SUMMARY Intravenous indomethacin was given to 36 neonates with a patent ductus arteriosus who where receiving ventilatory support for respiratory distress syndrome. Permanent closure of the ductus arteriosus occurred in $21(58 \%)$ infants and in this group the mean 24 hour plasma indomethacin concentration was $0.37 \mu \mathrm{g} / \mathrm{ml}$. Partial success was achieved in $6(17 \%)$ infants (mean 24 hour indomethacin concentration $0.34 \mu \mathrm{g} / \mathrm{ml}$ ) but in 9 patients (mean 24 hour indomethacin concentration $0.29 \mu \mathrm{g} / \mathrm{ml}$ ) there was no clinical change. Although the mean 24 hour indomethacin concentration was lower in the group with no clinical change, this was not statistically significant. Five of the 21 patients in whom there was permanent closure of the ductus required more than one dose of indomethacin. The possible effects of birthweight and age at indomethacin treatment were difficult to separate because of the high negative correlation between these two variables. The chance of closure was enhanced significantly if the patient had either a birthweight of at least $1 \mathrm{~kg}$ or the age at indomethacin treatment did not exceed 10 days, or both. Six hour but not 24 hour indomethacin concentrations were higher in patients with a high birthweight treated at an early age.

Indomethacin has gained wide acceptance as a potent constrictor of the ductus arteriosus in preterm infants with the respiratory distress syndrome. ${ }^{1-3}$ While both oral and rectal administration of indomethacin have led to variable closure rates $^{4-6}$ the closure rates with intravenous administration seem to be consistently higher. ${ }^{3}$ There have been no published studies from the United Kingdom on the use of intravenous indomethacin in ductal closure or on plasma indomethacin concentrations related to therapeutic effect. We have therefore studied the effect of this drug on preterm neonates who were being ventilated for active lung disease. We also measured the drug concentrations and related these to clinical effect.

\section{Patients and methods}

Preterm infants born in the West Yorkshire region who required ventilation for respiratory distress syndrome and were considered to have a haemodynamically patent ductus arteriosus were eligible for inclusion in the study. Twenty five of 38 infants were studied at one of two hospitals in Leeds; the remainder were at other hospitals in the region.
We used the following clinical and radiological criteria for the diagnosis of patent ductus arteriosus:

(1) A systolic murmur in the pulmonary area which did not have to extend throughout systole.

(2) Bounding peripheral pulses.

(3) Cardiomegaly and pulmonary plethora on chest radiograph.

Criteria for exclusion from treatment with intravenous indomethacin were:

(1) Tendency to excessive bleeding, a prolonged prothrombin time, prolonged partial thromboplastin time or a platelet count in peripheral blood of less than $100 \times 10^{9} / 1$.

(2) Recent haemorrhage or haemorrhagic illness.

(3) Poor urinary output and blood urea concentration of greater than $8 \mathrm{mmol} / \mathrm{l}$.

(4) Serum bilirubin concentration high enough to require treatment with phototherapy.

Before treatment with indomethacin all patients had been managed conservatively by fluid restriction (between 90 and $120 \mathrm{ml} / \mathrm{kg} / \mathrm{day}$ ) and parenteral frusemide for at least 24 hours. Daily 
measurements were made of blood urea and electrolytes and full blood counts including platelets were made before and after treatment with indomethacin.

The lyophilised indomethacin powder was supplied in vials under licence by Merck, Sharpe, and Dohme Research Laboratories. The powder was reconstituted with sterile water and injected as a bolus directly into a peripheral vein. The dose used was $0.2 \mathrm{mg} / \mathrm{kg}$ and was repeated at 24 hour intervals to a maximum of three doses. The infants were examined clinically 6 hours and 24 hours after the drug was given. The character of the murmur, ventilation settings, and results of routine blood gas estimations were noted.

Treatment was considered successful if the murmur disappeared and did not recur before discharge home. Partial success was assumed if the murmur disappeared but then recurred or if there was a diminution in the intensity of the murmur and a decrease in the volume of peripheral pulses with a corresponding reduction in ventilation requirements. Treatment was considered to have failed if there was no change in the character of the murmur and no reduction in ventilation requirements.

Two ml of capillary blood were taken at 6 and 24 hours. The plasma was separated by centrifugation and stored at $-20^{\circ} \mathrm{C}$ for up to four weeks before analysis. The plasma indomethacin concentration was measured by high performance liquid chromatography. ${ }^{7}$

\section{Results}

Fifty doses of intravenous indomethacin were given to 38 patients. Two patients were later shown to have other heart lesions-one had total anomalous pulmonary venous drainage and the second has an atrioventricular canal. Only the remaining 36 infants will be considered.

Pharmacologically induced closure of a patent ductus arteriosus occurred within 24 hours of the first dose of indomethacin in 16 patients $(45 \%)$ and after the second or third dose in a further five patients. The total closure rate was therefore $58 \%$ (Table). Partial success was achieved in 6 patients $(17 \%)$ and the drug was considered to have failed in $9(25 \%)$. Seven of the patients who failed to respond to medical management underwent surgical closure of the ductus arteriosus. In one patient ductal closure occurred 7 days after indomethacin treatment and in the remaining patient 8 days after treatment. In 12 of 21 of the successfully treated group weaning from ventilation was achieved by a mean of 3.5 days (range 1 to 8 days) from the time of indomethacin treatment.
Table Birthweight, age at indomethacin treatment, and outcome in 36 infants with patent ductus arteriosus

\begin{tabular}{|c|c|c|c|}
\hline & Success & Partial success & Failure \\
\hline Number $(n=36)$ & 21 & 6 & 9 \\
\hline \multicolumn{4}{|l|}{ Birthweight (g) } \\
\hline $\begin{array}{l}\text { Median } \\
\text { (Range) }\end{array}$ & $\begin{array}{l}1068 \\
(650-1700)\end{array}$ & $\begin{array}{l}1174 \\
(800-13(0))\end{array}$ & $\begin{array}{l}835 \\
(640-1080)\end{array}$ \\
\hline \multicolumn{4}{|c|}{ Age at treatment (dys) } \\
\hline $\begin{array}{l}\text { Mean } \\
\text { (Range) }\end{array}$ & $\begin{array}{l}7 \cdot 7 \\
(1-16)\end{array}$ & $\begin{array}{l}10 \cdot 2 \\
(4-20)\end{array}$ & $\begin{array}{l}16 \cdot 6 \\
(3-50)\end{array}$ \\
\hline \multicolumn{4}{|c|}{ Gestational age (wks) } \\
\hline $\begin{array}{l}\text { Mean } \\
\text { (Range) }\end{array}$ & $\begin{array}{l}29 \cdot 8 \\
(26-35)\end{array}$ & $\begin{array}{l}27 \cdot 4 \\
(25-29)\end{array}$ & $\begin{array}{l}28 \cdot 0 \\
(25-31)\end{array}$ \\
\hline
\end{tabular}

Birthweight and age at indomethacin treatment. Birthweight and age at indomethacin treatment were recorded in 35 patients and a high negative correlation between these two variables was found (Fig. 1) which prevented the separate statistical analysis of their effects.

Eighteen $(72 \%)$ of the 25 patients whose birthweight was $1 \mathrm{~kg}$ or more and who were aged 10 days or less when indomethacin treatment began were successfully treated; five $(20 \%)$ were partial successes and two $(8 \%)$ were treatment failures. Two $(20 \%)$ of the 10 patients whose birthweight was less than $1 \mathrm{~kg}$ and who were older than 10 days when indomethacin treatment began were successfully treated; one $(10 \%)$ was a partial success and 7 $(70 \%)$ were treatment failures. Analysing this data

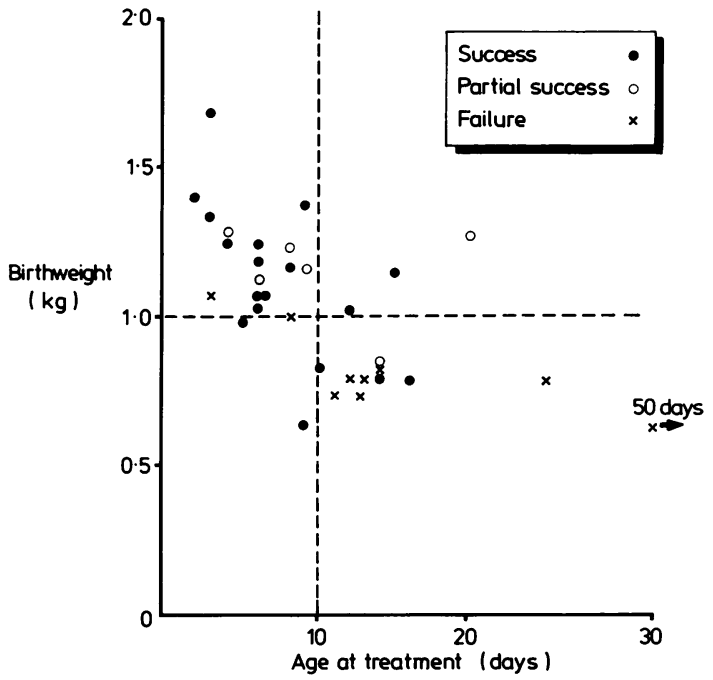

Fig. 1 Outcome in relation to age at indomethacin treatment and birthweight in 36 infants with patent ductus arteriosus. 
as a $3 \times 2$ contingency table, the difference in success rates between these two groups of patients was significant at the $5 \%$ level.

Plasma indomethacin concentration (single dose). The mean plasma indomethacin concentration at 6 hours in the successfully treated group was 0.59 $\mu \mathrm{g} / \mathrm{ml}$ (range $0 \cdot 10$ to $1.00 \mu \mathrm{g} / \mathrm{ml}$ ); in the partially treated group it was $0.53 \mu \mathrm{g} / \mathrm{ml}$ (range 0.16 to 0.80 $\mu \mathrm{g} / \mathrm{ml}$ ); in the non-responders it was $0.44 \mu \mathrm{g} / \mathrm{ml}$ (range 0.23 to $0.60 \mu \mathrm{g} / \mathrm{ml}$ ) (Fig. 2). The statistical analysis of this data using analysis of variance showed no significant differences in mean 6 hour indomethacin concentrations between the three groups.

The mean plasma indomethacin concentration at 24 hours in the successfully treated group was $0 \cdot 40$ $\mu \mathrm{g} / \mathrm{ml}$ (range 0.10 to $0.62 \mu \mathrm{g} / \mathrm{ml}$ ); in the partially treated group it was $0.34 \mu \mathrm{g} / \mathrm{ml}$ (range 0.06 to 0.66 $\mu \mathrm{g} / \mathrm{ml}$ ); in the non-responders it was $0.24 \mu \mathrm{g} / \mathrm{ml}$ (range 0.18 to $0.36 \mu \mathrm{g} / \mathrm{ml}$ ). The statistical analysis of this data using analysis of variance showed no significant differences in the mean 24 hour indomethacin concentration between the three groups.

Plasma indomethacin concentrations (multiple doses). Eleven patients were given more than one dose of indomethacin at 24 hour intervals; five responded fully and four failed completely. The mean 6 hour plasma concentration in the 11 patients was $0.61 \mu \mathrm{g} / \mathrm{ml}$ (range 0.22 to $1.00 \mu \mathrm{g} / \mathrm{ml}$ ) and the

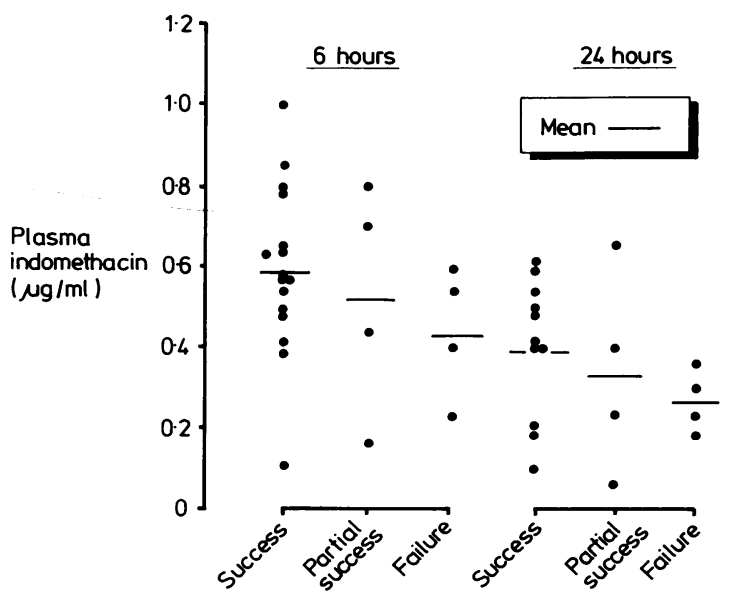

Fig. 2 Plasma indomethacin concentrations at 6 and 24 hours after intravenous indomethacin and clinical outcome in 36 infants with patent ductus arteriosus. mean 30 hour plasma concentration was $0.44 \mu \mathrm{g} / \mathrm{ml}$ (range 0.15 to $0.65 \mu \mathrm{g} / \mathrm{ml} \mathrm{(6} \mathrm{patients)).}$

The mean 24 hour plasma concentration was 0.34 $\mu \mathrm{g} / \mathrm{ml}$ (range 0.10 to $0.59 \mu \mathrm{g} / \mathrm{ml}$ (11 patients)) and the mean 48 hour plasma concentration was 0.33 $\mu \mathrm{g} / \mathrm{ml}$ (range 0.10 to $0.65 \mu \mathrm{g} / \mathrm{ml}$ (7 patients)).

Indomethacin concentration related to age at treatment and birthweight. The effects of age at treatment and birthweight on indomethacin concentrations were investigated by the statistical methodology of multiple regression analysis. For the 33 patients for whom the relevant data were recorded the 6 hour plasma indomethacin concentration was fitted by the equation:

Plasma indomethacin at 6 hours $=0.275-0.0024$

(Age (days) $+0 \cdot 30$ birthweight $(\mathrm{kg})$ ) .

This equation accounts for only $15 \%$ of the variation in the 6 hour plasma indomethacin concentration among the patients, is significant only at the $10 \%$ level, and thus either age or birthweight, or both have only a marginal effect on the 6 hour plasma indomethacin concentration.

As a result of the high negative correlation between the age at treatment and birthweight, the most acceptable interpretation of the above analysis is that the 6 hour indomethacin concentration is slightly higher on average for patients with higher birthweights and lower ages at treatment. This marginal effect had essentially disappeared by the time the 24 hour indomethacin samples were taken (30 patients) and a similar statistical analysis showed no significant effects of either age or birthweight, or both.

Side effects. There were no clinically significant changes in the blood parameters measured and no infant sustained any clinical deterioration after the indomethacin treatment.

\section{Discussion}

Persistent patency of the ductus arteriosus is a cause of increased morbidity and mortality ${ }^{8}$ in very low birthweight infants. Patency of a ductus arteriosus increases both oxygen dependency ${ }^{9}$ and the risk of developing bronchopulmonary dysplasia ${ }^{10}$ in those infants who require assisted ventilation. The incidence of patent ductus arteriosus in infants with birthweights under $1 \mathrm{~kg}$ is approximately $80 \%$ compared with $10 \%$ to $20 \%$ for those with birthweights greater than $1 \mathrm{~kg} .{ }^{3}$ This former group of infants is also more likely to develop bronchopulmonary dysplasia ${ }^{10}$ and eye oxygen toxicity. ${ }^{11}$

Spontaneous closure of a clinically detectable duct occurs in between $20 \%$ and $60 \%$ of patients ${ }^{8}$ 
but fluid restriction and the use of some diuretics increase this closure rate. Medical management has been expanded by the use of prostaglandin synthetase inhibitors, the most widely investigated one being indomethacin.

Early studies with oral and rectal indomethacin achieved closure rates that were marginally greater than those expected with conservative medical management. One explanation offered for these disappointing results was that the enteral absorption of indomethacin is unpredictable. ${ }^{12}$ The peak concentrations obtained in some of these patients were, however, similar to those found in patients after intravenous indomethacin treatment. ${ }^{4}$ The parenteral route has now been widely studied and reported ductal closure rates are encouragingly high-up to $85 \%$ in some series. ${ }^{3}$ Our closure rate after a single dose is disappointingly low at $45 \%$ but this may be explained by the fact that all our patients, unlike those of other studies, needed ventilation for active lung disease. Further doses increased the closure rate to $58 \%$. We did not persist with indomethacin in all of the nonresponders or partial responders but it may be that the reported prolonged elimination half life of the drug ${ }^{13}$ may have encouraged more of the ducts to close. This may explain why the two late closures occurred in the failed treatment group. Furthermore, for indomethacin to have been considered a success in our series the duct had to remain closed and it is now known that subsequent re-opening is common. ${ }^{14}$ In order to achieve ductal closure it is probable that repeated doses may be necessary by prolonging continuous exposure to the drug.

It is accepted that the factors that determine the chance of success are the age at indomethacin treatment ${ }^{3}{ }^{15}$ and the infant's birthweight. ${ }^{3}$ It was not possible statistically to separate birthweight and age at treatment in our study but there was a clear statistical relation between these variables and success. If the drug was given early (before 10 days of age) and to a larger infant (birthweight over $1 \mathrm{~kg}$ ) the chance of success was very high $(72 \%)$. These results are in keeping with the study of Firth and Pickering ${ }^{15}$ who reported that the success rate was greater than $75 \%$ in those patients treated before 12.5 days of age. Early 'prophylactic' closure of a patent ductus arteriosus has been reported by Mahoney et al ${ }^{9}$ who found that the only benefit obtained was a reduction in the duration of oxygen treatment to those patients with birthweights less than $1 \mathrm{~kg}$, thus confirming our observation of little success in these patients.

Variable plasma concentrations of the drug have been reported at both 6 hours and 24 hours after administration. ${ }^{16}$ This study confirms that there is a
10 fold variation in the 6 hour concentration and a 6 fold variation in the 24 hour concentration. Variations at later times after further doses are much less, being two or threefold.

Although there was no statistically significant difference between the concentrations achieved in patients of lower birthweight, there was a trend toward lower concentrations where birthweight was below $1 \mathrm{~kg}$. This finding is similar to that of Yeh $e t$ al. ${ }^{17}$ They gave $0.3 \mathrm{mg} / \mathrm{kg}$ of indomethacin intravenously and found that after four hours the plasma concentration was significantly lower for babies weighing less than $1 \mathrm{~kg}$ at birth than for those weighing more than $1 \mathrm{~kg}$. This may be explained by the increased body water as a proportion of body weight and hence the volume of distribution of the drug may be increased.

Nevertheless there seems to be no clear statistical relation between either 6 hour or 24 hour indomethacin concentrations and ductal closure. There did not seem to be a minimum effective concentration at 24 hours as suggested by Brash et $a l^{18}$ who reported that if the concentration fell below $0.25 \mu \mathrm{g} / \mathrm{ml}$ closure occurred in only one out of 7 patients compared with an $84 \%$ closure rate (32 out of 38) when the concentration was above 0.25 $\mu \mathrm{g} / \mathrm{ml}$. In our series 10 infants had a concentration below $0.25 \mu \mathrm{g} / \mathrm{ml}$ at 24 hours; in four of these ductal closure took place and four failed to respond. Brash et al suggested that monitoring of the plasma concentration between 6 and 24 hours after indomethacin treatment might be useful in predicting the need for further doses but our study failed to confirm this observation. More frequent administration (for example at 12 hourly intervals) may increase plasma concentrations but as we failed to show a clear concentration-effect relation this may not be any more successful than the 24 hour regimen.

We thank Merck, Sharpe, and Dohme Research Laboratories for supplying the indomethacin powder; Dr P J Dear, Dr G Lealman, Dr N Boyle, Dr G Wilson, Dr V Rajan, and Dr H Heggarty for permission to study the infants under their care; Dr A Baines for statistical advice; and Dr A Mehta for the indomethacin assays.

\section{References}

1 Friedman WF, Herschklan MJ, Printz MP, Pritlick PT, Kirkpatrick SE. Pharmacologic closure of patent ductus arteriosus in the premature infant. $N$ Engl $J$ Med 1976;295:526-9.

2 Yeh TF, Luken JA, Thalji A, Raval D, Carr I, Pildes RS. Intravenous indomethacin therapy in premature infants with persistent ductus arteriosus-a double blind controlled study. J Pediatr 1981;98:137-45.

${ }^{3}$ Bhat R, Fisher E, Raju TN, Vidyasagar D. Patent ductus arteriosus: recent advances in diagnosis and management. Pediatr Clin North Am 1982;29:1117-36.

4 Alpert BS, Lewins MJ, Rowland DW, et al. Plasma indomethacin levels in preterm newborn infants with symptomatic patent 
ductus arteriosus-clinical and echocardiographic assessment of response. J Pediatr 1979;95:578-82.

5 Yanagi RM, Wilson A, Newfeld EA, Aziz KU, Hunt CE. Indomethacin treatment for symptomatic patent ductus arteriosus. A double blind controlled study. Pediatrics 1981;67:647-52.

${ }^{6}$ Halliday HL, Hirata T, Brady JP. Indomethacin therapy for large patent ductus arteriosus in the low birth weight infant: results and complications. Pediatrics 1971;64:154-9.

7 Terweij-Groen CP, Heemstra S, Kraak JC. Rapid determination of indomethacin and salicylic acid in serum by means of reversed-phase liquid chromatography. $J$ Chromatogr 1980;181:385-97.

${ }^{8}$ Kitterman JA. Patent ductus arteriosus: Current clinical status. Arch Dis Child 1980;55:106-9.

9 Mahoney L, Garwero V, Brett C, Heymann MA, Clyman RI. Prophylactic indomethacin therapy in very low birth weight infants. N Engl J Med 1982;306:506-10.

10 Northway WH, Jnr. Observations on broncho-pulmonary dysplasia. J Pediatr 1979;95:815-8.

11 Gunn TR, Aranda JV, Little J. Incidence of retrolental fibroplasia. Lancet 1978;i:216.

12 Bhat R, Vidyasagar D, Vadapalli $M$, et al. Disposition of indomethacin in premature infants. $J$ Pediatr 1979;95:313-6.
13 Yaffe SJ, Friedman WF, Rogers D, Lang P, Ragni M, Saccar C. The disposition of indomethacin in preterm babies. $J$ Pediatr 1980;97:1001-6.

14 Rudd P, Montanez P, Hallidie-Smith K, Silverman M. Indomethacin treatment for patent ductus arteriosus in very low birthweight infants; a double blind trial. Arch Dis Child 1983;58:267-70.

15 Firth J, Pickering D. Timing of indomethacin in persistent ductus (letter). Lancet 1980;ii:144.

${ }^{16}$ Chiswick ML. Patent ductus arteriosus in premature babies. $\mathrm{Br}$ Med J 1981;283:1490-2.

17 Yeh TF, Luken J, Raval D, Thalji A, Carr I, Pildes RS. Indomethacin treatment in small versus large premature infants with ductus arteriosus. Br Heart J 1983;50:27-30.

18 Brash AR, Hickey DE, Graham TE, Stahlman MT, Oates JA, Cotton RB. Pharmacokinetics of indomethacin in the neonate. Relation of plasma indomethacin levels to response of the ductus arteriosus. N Engl J Med 1981;305:67-72.

Correspondence to $\mathrm{Dr} \mathrm{P}$ J Congdon, Clarendon Wing, The General Infirmary at Leeds, Belmont Grove, Leeds LS2 9NS.

Received 21 February 1984 